\title{
HDL and Sphingosine-1-phosphate Activate Stat3 in Prostate Cancer DU145 Cells via ERK1/2 and S1P Receptors, and Promote Cell Migration and Invasion
}

\author{
Yoshitaka Sekine ${ }^{1,2}$, Kazuhiro Suzuki ${ }^{2}$, and Alan T. Remaley ${ }^{1}$ \\ ${ }^{1}$ Lipoprotein Metabolism Section, Pulmonary and Vascular Medicine Branch, NHLBI, National \\ Institutes of Health, Bethesda, Maryland, USA \\ 2 Department of Urology, Gunma University Graduate School of Medicine, Maebashi, Gunma, \\ Japan
}

\section{Abstract}

BACKGROUND-Androgen deprivation therapy in men with prostate cancer leads to a significant increase of HDL, but the effect of HDL on prostate cancer is unknown. Recently, HDL, which transports sphingosine-1-phosphate (S1P), was reported to activate Signal transducer and activator of transcription 3 (Stat3) in cardiomyocytes. In this study, we examined the effect of HDL and S1P on Stat3 activation in prostate cancer cells and the involvement of S1P receptors in this process in 3 prostate cancer cell lines (PC-3, LNCaP and DU145).

\begin{abstract}
METHODS-Discordial reconstituted(r) HDL containing POPC, apoA-1 and S1P were prepared by the cholate dialysis method. The phosphorylations of Stat3, ERK1/2 and Akt were detected by Western blotting. Cell migration and invasion were determined by would healing assay and matrigel invasion chamber assay.
\end{abstract}

RESULTS-HDL increased Ser727 phosphorylation of Stat3, but not Tyr705 only in DU145 cells. S1P and rHDL-S1P also induced the phosphorylation, but not rHDL without S1P. They also induced DU145 cells migration and invasion. PD98059, a MEK inhibitor, and pertussis toxin, a Gi inhibitor, attenuated HDL-, S1P- and rHDL-S1P- induced Stat3 phosphorylation, whereas LY294002, a PI3K inhibitor, had no effect. Concerning S1P receptors, S1P1 expression was much lower than S1P2 and S1P3 in DU145 cells. Both JTE013, a S1P2 antagonist, and VPC23019, a S1P1/S1P3 antagonist, attenuated HDL-, S1P- and rHDL-S1P-induced Stat3 phosphorylations and cell migrations.

CONCLUSIONS-These results suggest that the change in HDL plasma levels by androgen deprivation therapy may alter prostate cancer growth and metastasis.

Correspondence: Yoshitaka Sekine, MD, PhD, Lipoprotein Metabolism Section, Pulmonary and Vascular Medicine Branch, NHLBI, National Institutes of Health, Building 10, Room 8N224, 9000 Rockville Pike, Bethesda, MD 20892 USA, Tel. +1-301-496-6220, Fax.+1-301-402-0190, ysekine@ showa.gunma-u.ac.jp, sekiney2@mail.nih.gov.

Conflict of interest statement

No potential conflicts of interest were disclosed. 


\section{Keywords}

HDL; S1P; Stat3; prostate cancer; DU145

\section{INTRODUCTION}

A high fat diet is not only an important risk factor for cardiovascular disease but also a number of cancers, including prostate cancer [1]. The mechanistic link between high fat diets and prostate cancer is not clearly established, but we have previously reported that low density lipoproteins and remnant lipoproteins increase prostate cancer cell proliferation [2,3]. High density lipoprotein (HDL) is beneficial in reducing atherosclerosis, in part, because of its role in removing excess cholesterol from cells [4], but also possibly because it is a growth factor for several cell types, including endothelial cells [5,6]. Androgen deprivation therapy in men with prostate cancer leads to a significant increase of HDL [7], but whether this has any effect on the development or progression of prostate cancer is unknown. Besides the role of HDL in cholesterol transport, HDL has many pleiotrophic effects on cells that could potentially effect prostate cancer cell progression [8]. HDL, for example, triggers the activation of ERK1/2, PI3K/Akt, which promotes cell growth and migration $[5,6,9]$.

Sphingosine 1-phosphate (S1P), a potent bioactive lipid, is delivered to cells, at least in part, by HDL [10]. S1P has many biologic effects of cells, including normal cells, such as altering cell migration, proliferation and angiogenesis $[9,11]$. Concerning cancer cells, S1P can induce cell motility, survival, growth and transformation via multiple pathways [12]. There are 5 types of G-protein coupled S1P receptors. S1P1, 2 and 3 are the most widely expressed, whereas S1P4 and S1P5 expression is confined to blood vascular cells and the central nervous system, respectively. Concerning prostate cancer, S1P has been shown to induce induced ERK1/2 and Akt activation, and proliferation in DU145 prostate cancer cells [13], but it has not been previously reported if the delivery of S1P by HDL can have a similar effect or whether HDL can alter cell migration and invasion.

Signal transducer and activator of transcription 3 (Stat3) is a well-known transcription factor, which is also involved in cell migration, invasion, proliferation and apoptosis in both normal and cancer cells, including prostate cancer [14]. Typically, prostate cancer cells have constitutively activated Stat3, and tumor motility is inhibited by blocking Stat 3 activation [14]. Clinically, there is also a relationship between local aggressiveness and Stat3 activation in prostate cancer tissue [15]. Stat3 usually requires both tyrosine (Tyr) 705 and serine (Ser) 727 phosphorylations for full transcriptional activity [16]. Just Ser 727 phosphorylation, however, it is sufficient to activate Stat 3 to drive prostate tumorigenesis independent of Tyr 705 phosphorylation [17]. Because HDL by delivering S1P has been shown to activate Stat3 in ventricular cardiomyocytes [18], we investigated, in this study, the possible link between HDL and cell signaling in prostate cancer cells. HDL and S1P were shown to activate ERK1/2 and Akt pathways in DU145 cells, leading to Stat3 phosphorylation. Furthermore, treatment of DU145 cells with HDL containing S1P was 
found to increase cell migration and invasion. These results suggest a potential role of HDL and S1P receptors in the pathogenesis of prostate cancer.

\section{MATERIALS AND METHODS}

\section{Cells and chemicals}

The human prostate cell lines DU145, PC-3 and LNCaP were purchased from American type culture collection (Manassas, VA). DU145 and cultured in DMEM (Sigma, St. Louis, MO); PC-3 and LNCaP in RPMI1640 (Sigma, St. Louis, MO), supplemented with $10 \%$ FBS (Moregate, Bulimba, Australia). The following antibodies were purchased from Cell Signaling (Beverly, MA): Antibodies rabbit anti-Stat3 polyclonal antibody, rabbit antiphospho-Stat3 (Ser727) polyclonal antibody, rabbit anti-phospho-Stat3 (Tyr705) polyclonal antibody, rabbit anti-ERK1/2 polyclonal antibody, rabbit anti-phospho-ERK1/2 (Thr202/ Tyr204) polyclonal antibody, rabbit anti-Akt polyclonal antibody and rabbit anti-phosphoAkt (Ser473) polyclonal antibody. S1P2 and S1P3 antibodies were purchased from Santa Cruz (Santa Cruz, CA). AG490, PD98059, PTX, and LY294002 were from Calbiochem (San Diego, CA). JTE013, VPC23019 and S1P were purchased from Tocris Bioscinence (Ellisville, MO), Avanti Polar Lipids (Alabaster, AL) and Avanti Polar Lipids, respectively.

\section{Isolation and labeling of lipoproteins}

Human plasma was collected from normal healthy volunteers. HDL (1.063-1.21 g/ml) was isolated by density gradient centrifugation [19]. Lipoproteins were dialyzed against $5 \mathrm{~L} \times 3$ of PBS ( $\mathrm{pH}$ 7.4) and then sterilized, using a $0.22 \mu \mathrm{m}$ filter unit (Millipore, Billerica, MA). Reconstituted (r) HDL containing POPC/A-1 or POPC/A-1/S1P (molar ratio; 92.5:1.0, 89:11:1, respectively) were prepared by the cholate dialysis method [20].

\section{Migration assay}

Cells were plated on a 12-well plate and grown to confluence. Thereafter, the medium was aspirated and cells were incubated with DMEM the medium, containing $0.1 \%$ bovine serum albumin (BSA) for $24 \mathrm{~h}$ before each experiment. $200 \mu \mathrm{l}$ tips were used to score the plates for making a denuded area. Cells were washed twice with PBS and treated with or without HDL, S1P or rHDL for $48 \mathrm{~h}$. Mitomycin $\mathrm{C}(0.5 \mu \mathrm{M})$ was also added to the medium for blocking cell proliferation. Cell migration into the wound area was examined by phasecontrast microscopy. Photographs were taken at 0 and $48 \mathrm{~h}$ and cell migration distance was determined by subtracting the values obtained at $0 \mathrm{~h}$ from $48 \mathrm{~h}$. Migration distances were expressed as fold change over the control. A representative experiment of at least two independent experiments is shown in each figure.

\section{Invasion assay}

Matrigel invasion chamber plates (Becton Dickinson/Biocoat, Bedford, MA) were used for this assay. Cells were incubated with DMEM, containing $0.1 \%$ bovine serum albumin (BSA) for $24 \mathrm{~h}$ before each experiment. Cells were plated in the upper chamber, with DMEM, containing HDL, S1P or rHDL; the lower chamber contained DMEM plus 1\% FBS and the same test ligands as the upper chamber. After $48 \mathrm{~h}$, non-invading cells were removed, by using a cotton swab. The numbers of cells that adhered to the bottom surface of 
the membrane were counted with at a microscope in several fields of duplicate membranes. The invasion index was expressed as fold change over the control.

\section{Quantification of mRNA levels}

mRNA levels were quantified, using an 7300 Real Time PCR System (Applied Biosystems, Austin, TX). Total RNA extraction and cDNA synthesis were performed [21], and PCR amplification was done, using $2 \mu \mathrm{l}$ of cDNA and S1P1, S1P2 and S1P3 primer (No. Hs00173499_m1, Hs01003373_m1 and Hs01019574_m1, respectively, Applied Biosystems). PCR was performed for one cycle of $10 \mathrm{~min}$ at $95{ }^{\circ} \mathrm{C}$, followed by 40 cycles of $15 \mathrm{~s}$ at $95^{\circ} \mathrm{C}$ and $60 \mathrm{~s}$ at $60^{\circ} \mathrm{C}$. For the internal control, Cyc (cyclophilin A) (No. 4326316E, Applied Biosystems) transcript levels were used. RQV (Relative Quantitation Value) were calculated, using the comparative CT $\left(2^{-\Delta \Delta \mathrm{Ct}}\right)$ cycle $(\Delta \mathrm{Ct})$ method [22].

\section{Western blotting assays}

Cell lysates were prepared in RIPA buffer (Pierce, Rockford, IL), containing $1 \mathrm{mM}$ sodium orthovanadate (Sigma) and protease inhibitors (Complete TM-without EDTA, Roche Diagnostics, Penzberg, Germany). Equal amounts of proteins (30-40 $\mu \mathrm{g} / \mathrm{lane})$ were electrophoresed on 4-12\% SDS-PAGE and transferred onto nitrocellulose membranes. Each membrane was incubated with the indicated primary antibody and was developed with a 1:1000 dilution of a HRP-conjugated secondary antibody (Cell Signaling). Proteins were visualized, using Western Lightning Plus-ECL (Perkin Elmer, Waltham, MA). A representative experiment of at least three independent experiments is shown in each figure.

SiRNA

Cells were seeded into a 12-well microtiter plate, with $10 \%$ FBS. Thereafter, cells were transfected with ON-TARGETplus Non-targeting Pool (No. D-001810-10-05, Dharmacon, Waltham, MA, USA) or ON-TARGETplus Stat3 siRNA (No. L-003544-00, Dharmacon), using DharmaFect 1 (Dharmacon). After transfection, cells were incubated for $48 \mathrm{~h}$ at $37{ }^{\circ} \mathrm{C}$ in a $5 \% \mathrm{CO}_{2}$ atmosphere.

\section{Statistical analysis}

All data, unless otherwise indicated, are expressed as the mean + SD. Differences between the values were evaluated by one-way analysis of variance (one-way ANOVA), with Tukey's post-hoc analysis. $\mathrm{P}$ values of less than 0.05 were considered statistically significant.

\section{RESULTS}

\section{HDL activated Ser727 Stat3 in DU145 cells}

Stat $3 \beta$ protein was detected in all three cell lines (PC-3, DU145 and LNCaP) cells, but Stat 3 a, the complete form of Stat3 [23], was only expressed in DU145 and LNCaP cells (Fig 1A). In DU145 cells, HDL was found to induce within $15 \mathrm{~min}$ a prompt increase in the phosphorylation of Ser727 of Stat3 a (Fig. 1B). HDL also caused the rapid phosphorylation of ERK1/2 and Akt, which then decreased in parallel over time (Fig 1B and C). All three 
proteins also showed a similar dose dependent effect, with maximum phosphorylation occurring with $500 \mu \mathrm{g} / \mathrm{mL}$ of HDL. Stat3 Tyr 705 was not observed to be phosphorylated in response to treatment with HDL. HDL also induced ERK1/2 phosphorylation in PC-3 cells but not in LNCaP cells (Fig. 1D). HDL did not induce the phosphorylation of Ser727 of Stat3 $\alpha$ in neither PC-3 nor LNCaP cells (Fig. 1D). No phosphorylation of Stat3 $\beta$ was observed in response to HDL treatment for any of the three cell lines.

\section{HDL induced migration and invasion of DU145 cells via Stat3 activation}

Next, we examined the effect of HDL treatment on DU145 cell migration by a wound healing assay (Fig. 2A). HDL induced the migration of DU145 cells in a dose dependent manner (Fig. 2A), with a similar dose dependent response as observed for the phosphorylation of Stat3 (Fig. 1B). HDL also induced the invasion of DU145 cells in a matrigel invasion chamber in a similar dose dependent manner (Fig 2B). We next investigated the effect of AG490, a JAK and Stat3 inhibitor, on HDL-induced Stat3 activation. AG490 inhibited HDL-induced Stat3 Ser727 activation (Fig. 2C) and also blocked the ability of HDL to stimulate the migration (Fig. 2D) and invasion (Fig. 2E) of DU145 cells. The expression of Stat 3 protein was inhibited after transfection with a Stat3 siRNA (Fig. 2F), which partially attenuated HDL-induced DU145 cell migration (Fig. 2G).

\section{Role of G-protein coupled receptors and ERK1/2 in HDL-induced Stat3 activation in DU145 cells}

The effect of PTX, a Gi protein inhibitor, the MEK inhibitor PD98059, and the PI3K inhibitor LY294002 on the phosphorylation of Stat3, ERK1/2 and Akt by HDL is shown in Fig. 3. Both PD98059 and PTX completely blocked HDL-induced phosphorylation of Stat3 and ERK1/2 (Fig. 3A). Both LY294002 and PTX also reduced HDL-induced phosphorylation of Akt, but LY294002 did not inhibit HDL-induced Stat3 activation (Fig. 3B). PTX and PD were also found to reduce HDL-induced DU145 cell migration (Fig. 3C).

\section{HDL induced Stat3 activation via S1P2 and S1P3 receptors}

The possible role of S1P receptors, which are G-coupled receptors [9], in HDL cell signaling, was examined in Fig. 4. Relatively high and nearly equal levels of mRNA were observed for S1P2 and S1P3 receptors in DU145 and LNCaP cells. Only PC-3 cells expressed significant quantities of S1P1 (Fig 4A). Similarly, all three cell lines expressed nearly equal amounts of S1P2 and S1P3 protein when tested by western blotting (Fig. 4B). To determine which S1P receptors affect HDL-induced Stat3 activation, we used JTE013, an S1P2 antagonist, and VPC23019, an S1P1/3 antagonist. Both JTE013 and VPC23019 attenuated HDL-induced Stat3 and ERK1/2 activation (Fig. 4C). Moreover, both antagonists also inhibited HDL-induced DU145 migration (Fig. 4D) and invasion (Fig. 4E). Because S1P1 is only expressed in limited amounts in DU145 cells (Fig. 4A), the inhibitor data suggests that both S1P2 and S1P3 receptors are involved in signal transduction by HDL.

\section{S1P and rHDL-S1P activate Stat3 in DU145 cells}

To further examine the role of S1P in HDL-induced Stat3 activation, we treated cells with just S1P versus reconstituted HDL made with S1P (rHDL-S1P) or without S1P (rHDL). 
Both S1P and rHDL-S1P were found to induce a prompt increase in Stat3 Ser727 and ERK1/2 phosphorylation (Fig. 5A-D). In contrast, rHDL only partially activated ERK1/2, and had no effect on Stat3 activation (Fig. 5E). In addition, S1P and rHDL-S1P induced DU145 cell migration (Fig. 5F) and invasion (Fig. 5G).

\section{S1P and rHDL-S1P activates activated Stat3 via S1P2 and S1P3 receptors in DU145 cells}

To further confirm that S1P and rHDL-S1P-induced Stat3 activation is mediated via ERK1/2 and S1P receptors in DU145 cells, we used various drug inhibitors and antagonists. PD98059, PTX, JTE013, and VPC0293 all attenuated both S1P and rHDL-S1P induced Stat 3 and ERK1/2 activations (Fig. 6A-F). Moreover, all of these agents also attenuated both S1P and rHDL-S1P induced DU145 cell migration (Fig. 6G).

\section{DISCUSSION}

The main finding from this study was that HDL induced Ser 727 phosphorylation of Stat3 in DU145 prostate cancer cells, which was dependent on the delivery of S1P and signaling by S1P2 and S1P3 receptors. Furthermore, activation of Stat 3 by HDL was also found to promote DU145 cell migration and invasion. The results also show that S1P2 and S1P3 are key players in Stat3 activation with HDL and S1P.

Stat 3 is activated by a wide range of cytokine and growth factors, such IL-6 and EGF $[14,16]$. After activation by phosphorylation, Stat3 forms a homodimer or a heterodimer with other members of the Stat family and is translocated to the nucleus where it has a wide range of effect on gene transcription. Many of the genes known to be regulated by Stat 3 are involved in cell growth and apoptosis. In case of prostate cancer, phosphorylated Stat 3 is known to be more abundant in aggressive type of prostate cancer samples [15]. Several growth factors and cytokines, such as EGF can induce migration, invasion and proliferation of prostate cancer cell lines via Stat3 activation [14]. Inhibition of Stat3 has been shown to cause apoptosis and growth inhibition in DU145 cells [25]. In the current study, HDL induced Ser 727 phosphorylation of Stat3 via ERK1/2, but not Tyr 705 (Fig. 1). Ser 727 phosphorylation is required for maximal activation of Stat3 signaling and is sufficient to activate Stat 3 to drive prostate tumorigenesis independent of Tyr 705 phosphorylation [17]. Recently, it was reported that HDL and S1P induced both Ser 727 and Tyr 705 phosphorylation in cardiomyocytes [18], but we only observed Ser 727 phosphorylation in prostate cancer cells after stimulation with HDL. Ser 727 phosphorylation of Stat3 has been reported to be induced through MAPK or mTOR pathways [18,25]. We also found that HDL induced both ERK1/2 and Akt phosphorylation, but only an inhibitor for ERK1/2 pathway decreased HDL and S1P-induced Ser727 phosphorylation (Fig. 3).

Activation of Stat3 by HDL appeared to be mediated based on its ability to deliver S1P to cells. S1P was also shown to mimic the same biologic responses observed with HDL, namely Stat3 phosphorylation, and induction of DU145 cell migration and invasion (Fig. 5). Furthermore, rHDL-S1P was found to activate in phosphorylating Stat3, whereas rHDL without S1P was inactive (Fig. 5). Because of its hydrophobic nature, approximately half of $\mathrm{S} 1 \mathrm{P}$ in blood is transported by HDL and is believed to be one of the major providers of extracellular S1P to cells [10]. S1P has widespread effects on cell function, which include 
proliferation, migration, angiogenesis, and trafficking $[9,20]$. The initial interaction of S1P with cells, including prostate cells [13], involves signaling through five specific $\mathrm{G}$ proteincoupled receptors S1P1-S1P5. We observed that the S1P2 and S1P3 receptors were equally expressed among three prostate cancer cell lines tested (DU145, PC-3 and LNCaP), but only PC-3 cells express high levels of S1P1. In many cell types, stimulation of S1P1 and S1P3 induces motility, whereas activation of S1P2 receptor inhibits migration [26]. HDL and S1P are reported to induce ERK1/2 and Stat 3 activation via S1P2 in cardiomyocytes [18]. Activation of Stat3 by treating DU145 cells with EGF also has been found to induce cell migration and invasion [14]. In this study, the inhibition of both S1P2 and S1P3 by various inhibitors attenuated HDL and S1P-induced cell migration and invasion of DU145 cells. S1P2 and S1P3 are coupled to Gi, G12/13 and Gq [26]. Gi is coupled with MAPK and Akt signal transduction, which induces cell migration. G12/13 is coupled to the Rho/Rho kinase pathway, which inhibits cell migration by blocking Rac. With regard to S1P2, G12/13 masks Gi-induced effects, and the overall result is the inhibition of cell migration by S1P [27]. In our study, S1P2 inhibitor attenuated HDL and S1P induced cell migration of DU145 cells; therefore, it appears that downstream effects of S1P2 in DU145 cells are predominated by Gi signaling.

In addition to its role in modulating the level of cellular cholesterol [4], HDL has many other pleiotrophic effects on cells that could potentially affect cancer cell growth. HDL, for example, triggers the activation of ERK1/2, PI3K/Akt [6,8], which can promote cell growth and migration $[28,29]$. Androgen deprivation therapy used in the treatment of advanced prostate cancer can significantly raise HDL. HDL typically increases between 8-20\% following androgen deprivation therapy [7]. One potential mechanism may be related to the inhibition of SR-BI expression by androgens, which would be expected to raise HDL levels [30].

Although most patients with prostate cancer, at least initially, respond well to androgen deprivation therapy, many prostate tumors eventually become androgen-independent, and then undergo accelerated growth. The results from this study suggest that the increase in HDL following androgen deprivation therapy may be detrimental, particularly for late stage prostate cancer. In our study, HDL increased migration and invasion of the androgen independent DU145 cell line; therefore, HDL may potentially accelerate the metastasis of hormone refractory prostate cancer. It is important to note that HDL and S1P induced Stat3 activation was not observed in the androgen-dependent LNCaP cell line. Recently, we reported that HDL does not activate signal transduction in the LNCaP cells, because of down regulation of ABCA1 by androgens [31]. PC-3 cells, which are also androgenindependent like DU145 cells, also did not respond to S1P treatment (data not shown). The cells, however, do not express Stat3 a (Fig. 1), the complete form of Stat3 [23], which likely accounts for lack of ability to respond to S1P treatment. Most human prostate cancer tissues have been shown to express activated Stat3 [15] and may, therefore, respond to HDL and S1P when they become androgen-independent, but in vivo animal or human studies will be needed to more definitively establish the effect of HDL on prostate cancer progression.

In summary, HDL and S1P were found to induce Stat3 activation, cell migration and invasion via S1P2 and S1P3 in androgen independent prostate cancer DU145 cells. These 
results suggest that epidemiologic and dietary studies examining the possible association of HDL and S1P plasma levels with prostate cancer may uncover a possible connection between lipoprotein metabolism and the pathogenesis of prostate cancer.

\section{Acknowledgments}

Research by ART and YS was supported by intramural NHBLI funding from the National Institutes of Health.

\section{References}

1. Hsing AW, Tsao L, Devesa SS. International trends and patterns of prostate cancer incidence and mortality. Int J Cancer. 2000; 85:60-67. [PubMed: 10585584]

2. Chen Y, Hughes-Fulford M. Human prostate cancer cells lack feedback regulation of low-density lipoprotein receptor and its regulator, SREBP2. Int J Cancer. 2001; 91:41-45. [PubMed: 11149418]

3. Sekine Y, Koike H, Nakano T, Nakajima K, Suzuki K. Remnant lipoproteins stimulate proliferation and activate MAPK and Akt signaling pathways via G protein-coupled receptor in PC-3 prostate cancer cells. Clin Chim Acta. 2007; 383:78-84. [PubMed: 17512923]

4. Remaley AT, Amar M, Sviridov D. HDL-replacement therapy: mechanism of action, types of agents and potential clinical indications. Expert Rev Cardiovasc Ther. 2008; 6:1203-1205. [PubMed: 18939908]

5. Cao WM, Murao K, Imachi H, Yu X, Abe H, Yamauchi A, Niimi M, Miyauchi A, Wong NC, Ishida T. A mutant high-density lipoprotein receptor inhibits proliferation of human breast cancer cells. Cancer res. 2004; 64:1515-1521. [PubMed: 14973113]

6. Miura S, Fujino M, Matsuo Y, Kawamura A, Tanigawa H, Nishikawa H, Saku K. High density lipoprotein-induced angiogenesis requires the activation of Ras/MAP kinase in human coronary artery endothelial cells. Arterioscler Thromb Vasc Biol. 2003; 23:802-808. [PubMed: 12637339]

7. Smith MR, Lee H, McGovern F, Fallon MA, Goode M, Zietman AL, Finkelstein JS. Metabolic changes during gonadotropin-releasing hormone agonist therapy for prostate cancer: differences from the classic metabolic syndrome. Cancer. 2008; 112:2188-2194. [PubMed: 18348297]

8. Nofer J, Assmann G. Atheroprotective affects of high-density lipoprotein-associated lysosphingolipids. Trends Cardiovasc Med. 2005; 15:265-271. [PubMed: 16226682]

9. Kimura T, Sato K, Malchinkhuu E, Tomura H, Tamama K, Kuwabara A, Murakami M, Okajima F. High-density lipoprotein stimulates endothelial cell migration and survival through sphingosine 1phosphate and its receptors. Arterioscler Thromb Vasc Biol. 2003; 23:1283-1288. [PubMed: 12775579]

10. Murata N, Sato K, Kon J, Tomura H, Yanagita M, Kuwabara A, Ui M, Okajima F. Interaction of sphingosine 1-phosphate with plasma components, including lipoproteins, regulates the lipid receptor-mediated actions. Biochem J. 2000; 352:809-815. [PubMed: 11104690]

11. Miura S, Tanigawa H, Matsuo Y, Fujino M, Kawamura A, Saku K. Ras/Raf1-dependent signal in sphingosine-1-phosphate-induced tube formation in human coronary artery endothelial cells. Biochem Biophys Res Comm. 2003; 306:924-929. [PubMed: 12821130]

12. Pyne NJ, Pyne S. Sphingosine 1-phosphate and cancer. Nat Rev Cancer. 2010; 10:489-503. [PubMed: 20555359]

13. Gibbs TC, Rubio MV, Zhang Z, Xie Y, Kipp KR, Meier KE. Signal transduction responses to lysophosphatidic acid and sphingosine 1-phosphate in human prostate cancer cells. Prostate. 2009; 69:1493-1506. [PubMed: 19536794]

14. Zhou W, Grandis JR, Wells A. STAT3 is required but not sufficient for EGF receptor-mediated migration and invasion of human prostate carcinoma cell lines. Br J Cancer. 2006; 95:164-171. [PubMed: 16804520]

15. Horinaga M, Okita H, Nakashima J, Kanao K, Sakamoto M, Murai M. Clinical and pathologic significance of activation of signal transducer and activator of transcription 3 in prostate cancer. Urology. 2005; 66:671-675. [PubMed: 16140113] 
16. Sengupta TK, Talbot E, Scherle PA, Ivanshkiv LB. Rapid inhibition of interleukin-6 signaling and Stat 3 activation mediated by mitogen activated protein kinase. Proc Natl Acad Sci USA. 1998; 95:11107-11112. [PubMed: 9736697]

17. Qin HR, Kim HJ, Kim JY, Hurt EM, Klarmann GJ, Kawasaki BT, Duhagon Serrat MA, Farrar WL. Activation of signal transducer and activator of transcription 3 through a phosphomimetic serine 727 promotes prostate tumorigenesis independent of tyrosine 705 phosphorylation. Cancer Res. 2008; 68:7736-7741. [PubMed: 18829527]

18. Frias MA, James RW, Gerber-Wicht C, Lang U. Native and reconstituted HDL activate Stat 3 in ventricular cardiomyocytes via ERK1/2: role of sphingosine-1-phosphate. Cardiovasc Res. 2009; 82:313-323. [PubMed: 19151362]

19. Redgrave TG, Roberts DC, West CE. Separation of plasma lipoproteins by density-gradient ultracentrifugation. Anal Biochem. 1975; 65:42-49. [PubMed: 165752]

20. Matsuo Y, Miura S, Kawamura A, Uehara Y, Rye KA, Saku K. Newly developed reconstituted high-density lipoprotein containing sphingosine-1-phosphate induces endothelial tube formation. Atherosclerosis. 2007; 194:159-168. [PubMed: 17118370]

21. Suzuki K, Koike H, Matsui H, Ono Y, Hasumi M, Nakazato H, Okugi H, Sekine Y, Oki K, Ito K, Yamamoto T, Fukabori Y, Kurokawa K, Yamanaka H. Genistein, a soy isoflavone, induces glutathione peroxidase in the human prostate cancer cell lines LNCaP and PC-3. Int J Cancer. 2002; 99:846-852. [PubMed: 12115487]

22. Livak KJ, Schmittgen TD. Analysis of relative gene expression data using real-time quantitative PCR and the 2 $\triangle \Delta C T$ method. Methods. 2001; 25:402-408. [PubMed: 11846609]

23. Caldenhoven E, van Dijk TB, Solari R, Armstrong J, Raaijmakers JA, Lammers JW, Koenderman L, de Groot RP. STAT3beta, a splice variant of transcription factor STAT3, is a dominant negative regulator of transcription. J Biol Chem. 1996; 271:13221-13227. [PubMed: 8675499]

24. Hellsten R, Johansson M, Dahlman A, Dizeyi N, Sterner O, Bjartell A. Galiellalactone is a novel therapeutic candidate against hormone-refractory prostate cancer expressing activated Stat 3. Prostate. 2008; 68:269-280. [PubMed: 18163422]

25. Yokogami K, Wakisaka S, Avruch J, Reeves SA. Serine phosphorylation and maximal activation of STAT3 during CNTF signaling is mediated by the rapamycin target mTOR. Curr Biol. 2000; 10:47-50. [PubMed: 10660304]

26. Okajima F, Sato K, Kimura T. Anti-atherogenic actions of high-density lipoprotein through sphingosine 1-phosphate receptors and scavenger receptor class B type I. Endocr J. 2009; 56:317334. [PubMed: 18753704]

27. Sugimoto N, Takuwa N, Okamoto H, Sakurada S, Takuwa Y. Inhibitory and stimulatory regulation of Rac and cell motility by the G12/13-Rho and Gi pathways integrated downstream of a single G protein-coupled sphingosine-1-phosphate receptor isoform. Mol Cell Biol. 2003; 23:1534-1545. [PubMed: 12588974]

28. Chuanhai G, Louis ML, David TP. Mitogenic signaling in androgen sensitive and insensitive prostate cancer cell lines. J Urol. 2000; 163:1027-1032. [PubMed: 10688043]

29. Kane LP, Mollenauer MN, Xu Z, Turck CW, Weiss A. Akt-dependent phosphorylation specifically regulates Cot induction of NF-kappa B-dependent transcription. Mol Cell Biol. 2002; 22:59625974. [PubMed: 12138205]

30. Langer C, Gansz B, Goepfert C, Engel T, Uehara Y, von Dehn G, Jansen H, Assmann G, von Eckardstein A. Testosterone up-regulates scavenger receptor BI and stimulates cholesterol efflux from macrophages. Biochem Biophys Res Commun. 2002; 296:1051-1057. [PubMed: 12207878]

31. Sekine Y, Demosky SJ, Stonik JA, Furuya Y, Koike H, Suzuki K, Remaley AT. High-Density Lipoprotein Induces Proliferation and Migration of Human Prostate Androgen-Independent Cancer Cells by an ABCA1-Dependent Mechanism. Mol Cancer Res. 2010 in press. 
A

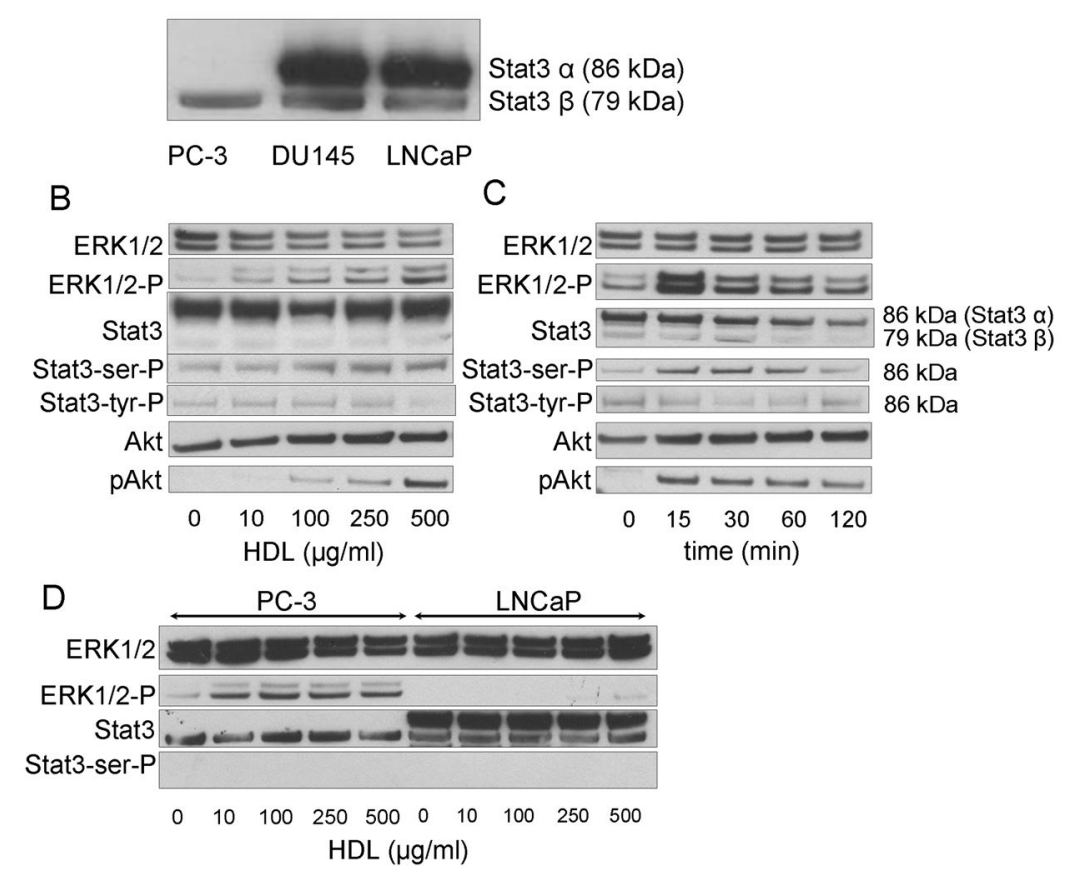

Fig. 1.

Stat 3 activation in prostate cancer cells by HDL. A: Western blotting of Stat 3 protein levels in prostate cancer cell lines. B, C: DU145 cells cultured in the medium without FBS for $24 \mathrm{~h}$ were analyzed for Stat3, ERK1/2, and Akt phosphorylation by western blotting after HDL treatment at the indicated concentration (Panel B; $30 \mathrm{~min}$ ) or for the indicated times with HDL (Panel C; HDL $500 \mu \mathrm{g} / \mathrm{mL}$ ). D: PC-3 and LNCaP Cells cultured in the medium without FBS for $24 \mathrm{~h}$ were analyzed by western blotting for ERK1/2 and Stat3 phosphorylation after $30 \mathrm{~min}$ with the indicated concentration of HDL. 

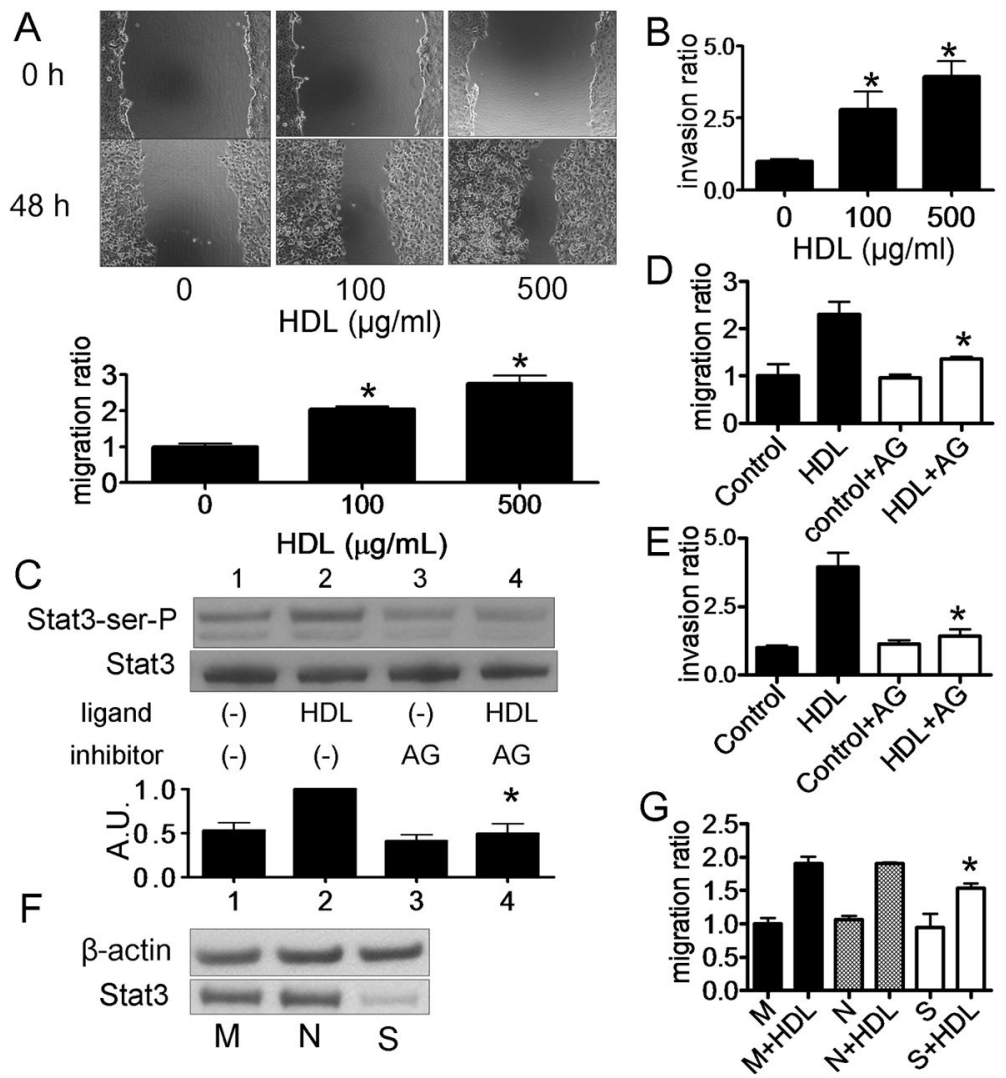

Fig. 2.

Migration and invasion of DU145 cells by HDL via Stat3 activation. A, D: A monolayer of DU145 cells were scored and then cultured in medium for 0 or $48 \mathrm{~h}$ with or without HDL. Cell migration into the wound was examined by phase-contrast microscopy. Cells were preincubated in the absence (-) or presence of AG490 $(50 \mu \mathrm{M})$ for $16 \mathrm{~h}$ before HDL treatment (Panel D). Values are expressed as the mean $+\mathrm{SD}(\mathrm{n}=3)$. ${ }^{*} P<0.01 \mathrm{vs} 0 \mu \mathrm{g} / \mathrm{mL}$.

AG; AG490. B, E: After culturing DU145 cells with HDL, the numbers of cells that invaded through the matrigel were counted at the microscope. Cells were preincubated in the absence (Control) or presence of AG490 $(50 \mu \mathrm{M})$ for $16 \mathrm{~h}$ before HDL treatment (Panel E). Values are expressed as the mean $+\mathrm{SD}(\mathrm{n}=3)$. $* P<0.05$ vs $0 \mu \mathrm{g} / \mathrm{mL}$ (Panel B), $* P<0.05$ vs HDL (Panel E). C: DU145 cells were preincubated in the absence (-) or presence (+) of AG490 $(50 \mu \mathrm{g} / \mathrm{mL})$ for $16 \mathrm{~h}$, and then incubated with or without HDL $(500 \mu \mathrm{g} / \mathrm{ml})$ for $15 \mathrm{~min}$. Whole cell lysate was analyzed by western blotting. The graph shows the ratio of pStat 3 to Stat 3 in each sample relative to 1.0 for lane $2(n=3$, mean $+\mathrm{SD})$. $* P<0.05$ vs lane 2 . AU; arbitrary unit F: Effect of siRNA for Stat3 expression in DU145 cells was evaluated. Mock transfected cells (M) or cells transfected with Stat3 siRNA (S) or negative control siRNA $(\mathrm{N})$, cells were incubated for $48 \mathrm{~h}$ before harvest for western blotting. G: After transfection of siRNA, DU145 cells were incubated with the medium containing $10 \%$ FBS for $24 \mathrm{~h}$, and medium was switched to serum-free medium. After $24 \mathrm{~h}$, cells were wounded and then cultured for 0 or $48 \mathrm{~h}$ with or without HDL $(500 \mu \mathrm{g} / \mathrm{mL})$. Cell migration into the wound was examined by phase-contrast microscopy. Values are expressed as the mean $+\mathrm{SD}$. $(n=3)$. *P<0.05 vs N+HDL. M; mock, N; negative and S; Stat3. 

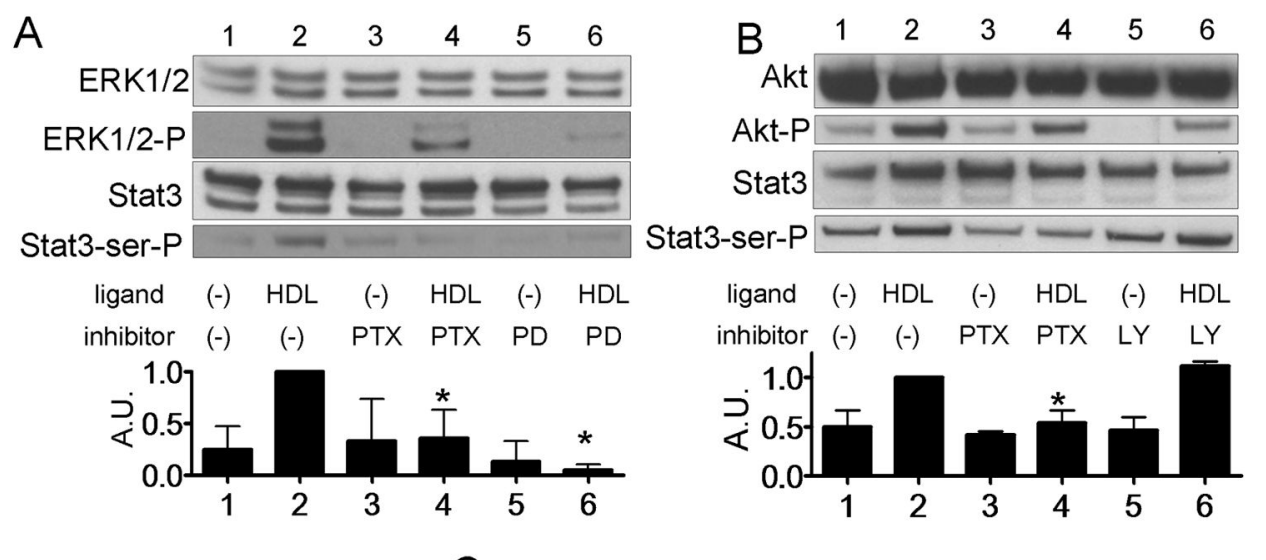

C

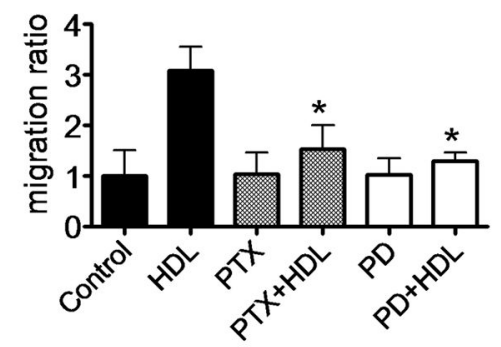

Fig. 3.

Stat3 activation by HDL via ERK1/2 and G-coupled receptor in DU145 cells. A, B: DU145 cells were preincubated in the absence $(-)$ or presence $(+)$ of PTX $(100 \mathrm{ng} / \mathrm{mL})$ for $24 \mathrm{~h}$, PD98059 $(2.5 \mu \mathrm{M})$ for $1 \mathrm{~h}$ or LY294002 $(2.5 \mu \mathrm{M})$ for $1 \mathrm{~h}$. Cellscells were incubated with or without HDL ( $500 \mu \mathrm{g} / \mathrm{ml}$ ) for $15 \mathrm{~min}$, and whole cell lysate was analyzed by western blotting (A and B). The graph shows the ratio of pStat 3 to Stat 3 in each sample relative to 1.0 for lane $2(\mathrm{n}=3$, mean $+\mathrm{SD}) . * P<0.05$ vs lane 2 . C: Cells were wounded and then cultured for 0 or $48 \mathrm{~h}$ with or without HDL $(500 \mu \mathrm{g} / \mathrm{mL})$. Cell migration into the wound was examined by phase-contrast microscopy. Values are expressed as the mean $+\mathrm{SD} * P<0.01$ vs HDL. 


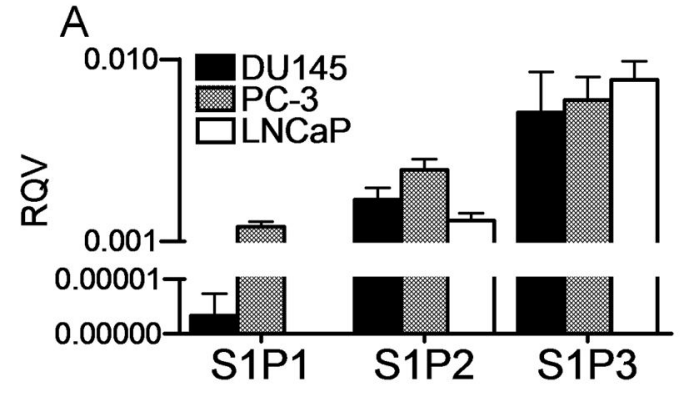

\section{B}
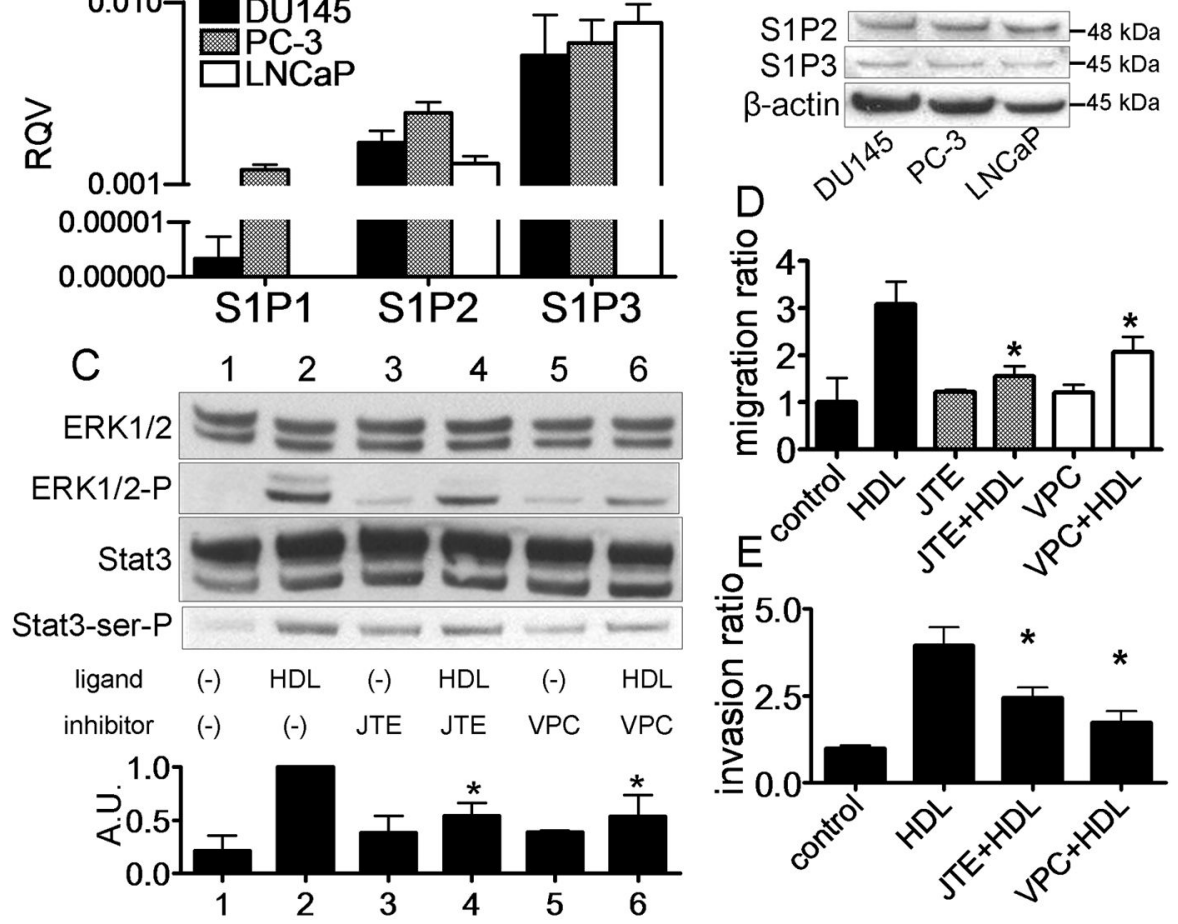

Fig. 4.

Stat 3 activation by HDL via S1P2 and S1P3 in DU145 cells. A: mRNA levels of S1P1, S1P2 and S1P3 were evaluated by real time PCR and expressed as RQV compared to Cyc. Values are expressed as the mean $+\mathrm{SD}(\mathrm{n}=3)$. B; Protein levels of S1P2 and S1P3 were evaluated by western blotting. C-D: DU145 cells were preincubated in the absence (-) or presence of JTE013 $(5 \mu \mathrm{M})$ for $1 \mathrm{~h}$, and VPC23019 $(5 \mu \mathrm{M})$ for $1 \mathrm{~h}$. Cells were incubated with or without HDL (500 $\mu \mathrm{g} / \mathrm{ml}$ ) for $15 \mathrm{~min}$, and whole cell lysate was analyzed by western blotting (Panel B). The graph shows the ratio of Stat3-ser-P to Stat3 in each sample relative to 1.0 for lane $2(\mathrm{n}=3$, mean $+\mathrm{SD})$. $* P<0.05$ vs lane 2 . (Panel C). Cells were wounded and then cultured for 0 or $48 \mathrm{~h}$ with or without HDL $(500 \mu \mathrm{g} / \mathrm{mL})$. Values are expressed as the mean $+\mathrm{SD} * P<0.05$ vs HDL (Panel D). After culturing DU145 cells with HDL, the numbers of cells that invaded through the matrigel were microscopically counted. Values are expressed as the mean $+\mathrm{SD}(\mathrm{n}=3) . * P<0.01$ vs HDL (Panel E). 

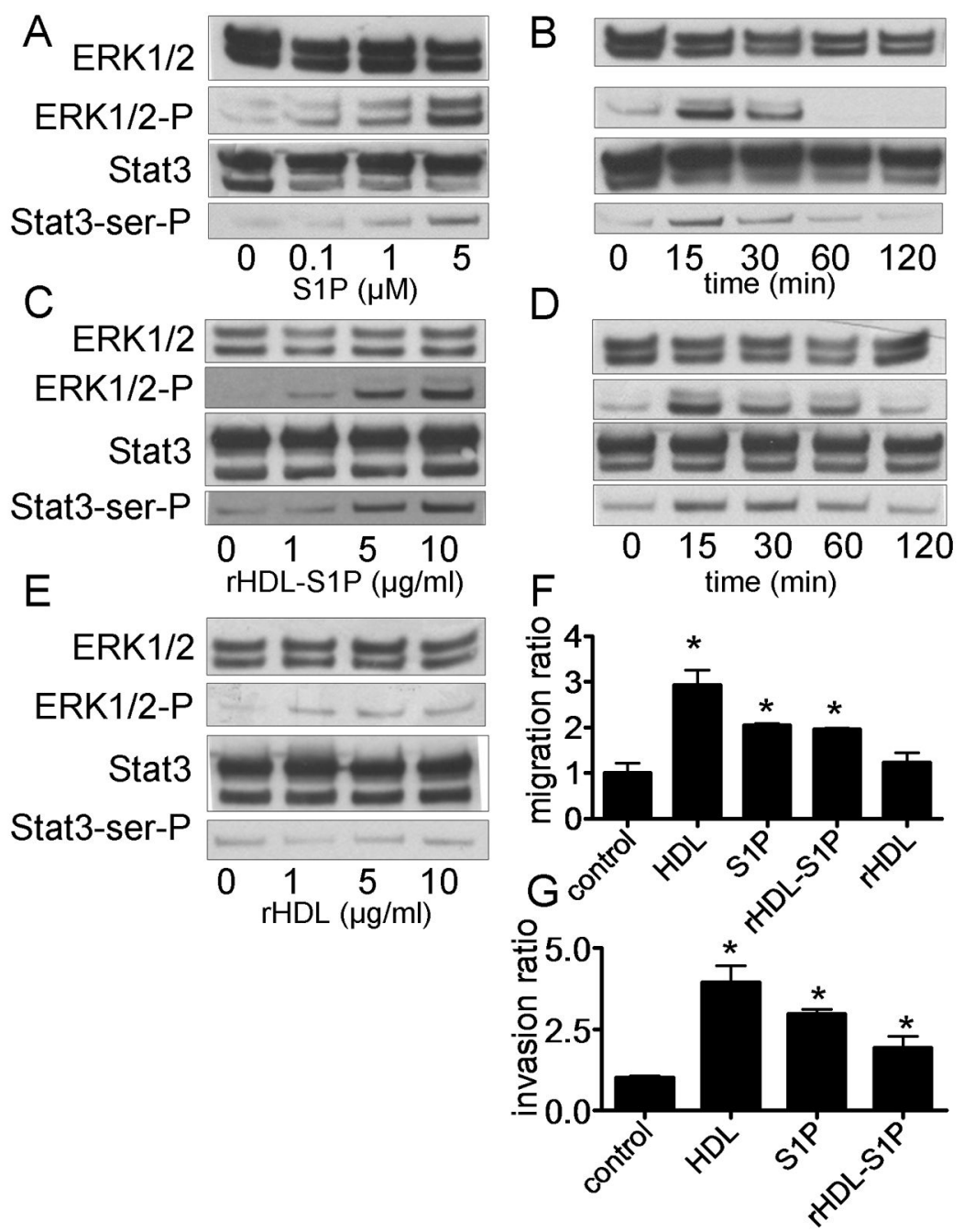

Fig. 5.

Stat3 activation by S1P, rHDL-S1P and rHDL. A-E: DU145 cells cultured in medium without FBS for $24 \mathrm{~h}$ were analyzed by western blotting after 15 min (Panel A, C and E) for the indicated concentration of S1P (Panel A), rHDL-S1P (Panel C) or rHDL (Panel E), or after treatment for the indicated times with S1P (Panel B; S1P $5 \mu \mathrm{M}$ ) or rHDL-S1P (Panel D; $10 \mu \mathrm{g} / \mathrm{ml})$. F: DU145 cells were wounded and cultured in the medium for 0 or $48 \mathrm{~h}$ with or without S1P $(5 \mu \mathrm{M})$, rHDL-S1P $(10 \mu \mathrm{g} / \mathrm{ml})$, or rHDL $(10 \mu \mathrm{g} / \mathrm{ml})$. Cell migration into the wound was examined by phase-contrast microscopy. Values are expressed as the mean $+\mathrm{SD}$ $(\mathrm{n}=3) . * P<0.01$ vs control. G: After culturing DU145 cells with S1P $(5 \mu \mathrm{M})$ or rHDL-S1P $(10 \mu \mathrm{g} / \mathrm{ml})$, the numbers of cells that went through the matrigel were counted at the microscope. Values are expressed as the mean $+\mathrm{SD}(\mathrm{n}=3)$. $* P<0.05$ vs control. 

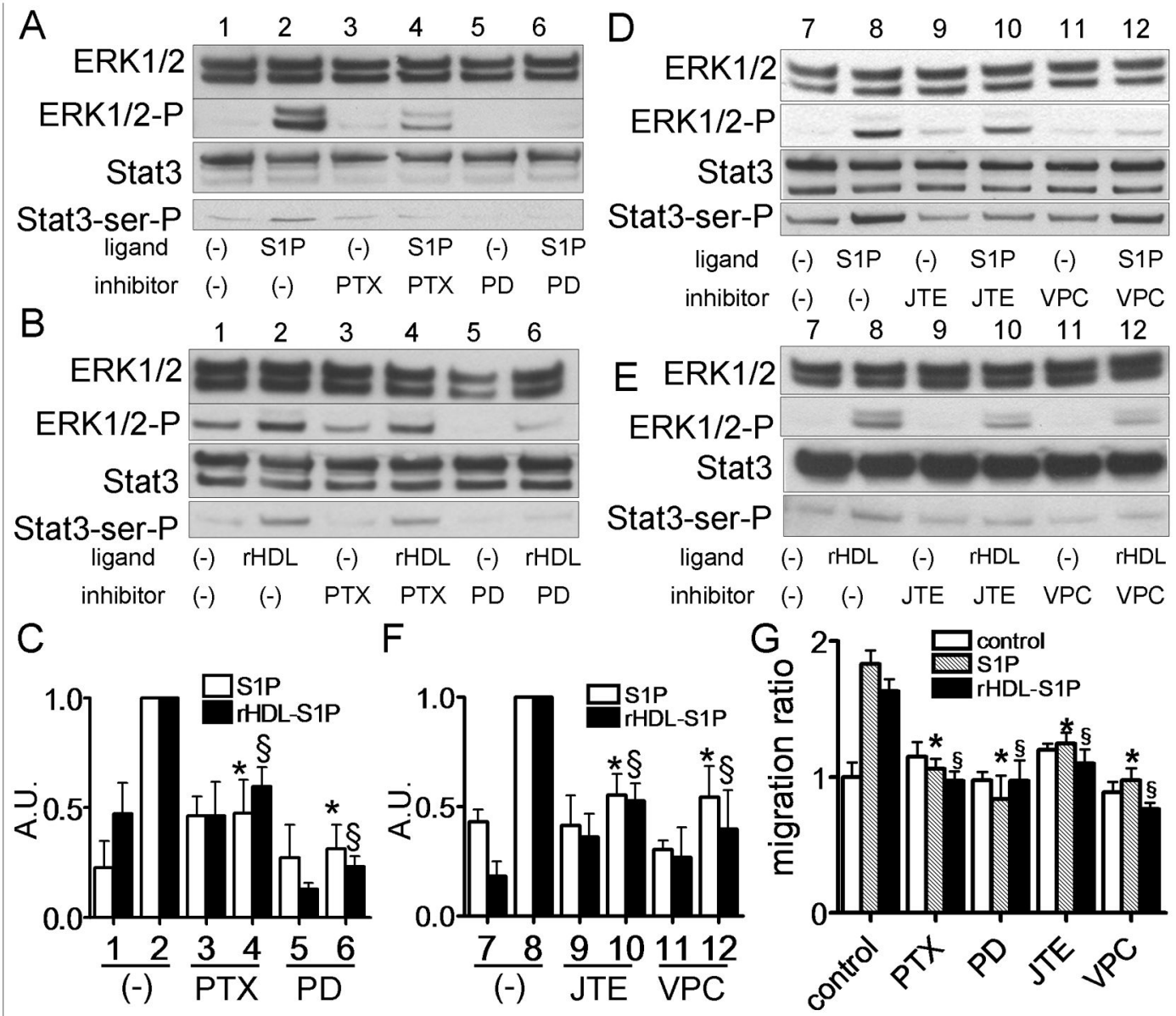

Fig. 6.

Stat 3 activation by S1P and rHDL-S1P via S1P2 and S1P3 in DU145 cells. A-F: DU145 cells were preincubated in the absence $(-)$ or presence of PTX $(100 \mathrm{ng} / \mathrm{mL})$ for $24 \mathrm{~h}$, PD98059 $(2.5 \mu \mathrm{M})$ for $1 \mathrm{~h}$, JTE013 $(5 \mu \mathrm{M})$ for $1 \mathrm{~h}$ or VPC23019 $(5 \mu \mathrm{M})$ for $1 \mathrm{~h}$. Cells were incubated with or without S1P $(5 \mu \mathrm{M})$ (Panel A and B) or rHDL-S1P $(10 \mu \mathrm{g} / \mathrm{ml})($ Panel D and E) for $15 \mathrm{~min}$, and whole cell lysate was analyzed by western blotting. The graph shows the ratio of Stat3-ser-P to Stat3 in each sample relative to 1.0 for lane $2(n=3$, mean $+S D)$. The results of Panel A and B, and Panel D and E were shown in Panel C and D, respectively. ${ }^{*} P<0.05$ vs lane 2 of S1P, $\S P<0.05$ vs lane 2 of rHDL-S1P. G: Cells were wounded and then cultured for 0 or $48 \mathrm{~h}$ with or without S1P $(5 \mu \mathrm{M})$ or rHDL-S1P $(10 \mu \mathrm{g} /$ $\mathrm{ml})$. Cell migration into the wound was examined by phase-contrast microscopy. Values are expressed as the mean $+\mathrm{SD}$. ${ }^{*} P<0.05$ vs control of S1P, $\S P<0.05$ vs. control of rHDL-S1P. 